\title{
DESIGN PROJECT VALIDATION FOR THE GREENFIELD COALITION FOR NEW MANUFACTURING EDUCATION
}

\author{
Ece Yaprak \\ Wayne State University \\ Attila Yaprak \\ Wayne State University \\ David L. Wells \\ Focus:HOPE \\ Center for Advanced Technologies
}

\begin{abstract}
The Greenfield Coalition is a National Science Foundation funded coalition which sets a new paradigm in manufacturing engineering education. One of the key goals of the coalition is the development of a unique, experiential, learner-centered curricula which is designed and delivered through the collaboration of university and industry partners. Engineering technologist candidates are full time employees of the Center for Advanced Technology (CAT) Center where their real world experience plays an important role in their educational program. In this paper, we discuss our experience in the development of a portfolio of validation methods in the Design Project Knowledge area, a senior capstone design course in engineering technology at Wayne State University (WSU) by validating these candidates' manufacturing experiences at the CAT Center.
\end{abstract}

\section{INTRODUCTION}

The last two decades have been marked by the globalization of markets, technology, and competition. This transformation has necessitated sharpened skills and competencies in engineering technologies that are relevant to the business community's needs, An important area in which the need for sharper competencies has increased recently is engineering technology. This is due to at least two reasons: (1) engineering technology has become a more critical value-adding activity and cost containment domain in the manufacturing value chain, and (2) integrating continuously improving design competencies into the manufacturing process, indeed the entire value chain, has become a lucrative source of competitive advantage in competing against relevant rivals. This is evidenced by the following: (i) many Michigan manufacturers have recently embarked upon improved design methodologies as key components of their quest to achieve manufacturing excellence; (ii) many universities have incorporated (or are incorporating) quality concepts into their curricula, research, and administrative processes; and (iii) many industry-university-government partnerships, such as the Greenfield Coalition (CC), are 
emerging to leverage resources in the journey toward achieving industrial and academic excellence in global competition.

These profound transformations have also altered our traditional notions about engineering education, especially the teaching of engineering design. The traditional domain of engineering design consisted of a sequential process ranging typically, from need identification, concept-testing, feasibility analysis, mechanical design, prototype development, and aesthetic improvements, to commercialization. This iterative process has become too cumbersome, too costly, and too rigid for today's needs as it does not allow for flexibility in the face of rapidly changing market scenarios. Increased global competition and the urgent need to respond to market demands swiftly, however, now necessitates a more revolutionary approach to the teaching and validation of engineering design. This approach includes (i) student involvement along all phases of product or process development and reporting; (ii) validation of "lessons learned" along selected phases of engineering design projects; (iii) commitment to total quality during the entire design process; and (iv) integrating lessons learned from industrial partners.

We are in the process of developing validation methods for the CAT candidates' design projects. Unlike the traditional approach to capstone design, our goal is to validate the GC candidate's learning in engineering technology design (during his/her real life manufacturing work experience at the CAT Center) by assessing his/her acquisition and internalization of a portfolio of competencies which we have grouped into Process, Human Skills, and Continuous Improvement modules after his/her design has been completed. That is, we will measure, through a formalized validation process, the candidate's absorption of, and his ability to synthesize, these competencies through a set of workproducts (portfolio, written synthesis and oral scrutiny) and outputs (validation of the candidate's capstone design work at WSU).

\section{VALIDATION METHOD DEVELOPMENT}

The scope of our project builds upon the fundamental features which define the Greenfield Coalition's vision and approach to engineering education: innovative curriculum; computer-aided instruction; and creative, student-centered learning. Embedded into our scope are many of the competencies which are targeted by the Coalition. Indeed, we validate the acquisition and internalization of these competencies by the GC candidates as they are about to complete their Focus:HOPE education and embark upon professional careers. The candidate's hands-on manufacturing skills and their interdisciplinary knowledge at the CAT Center during their tenure, will be applied to acquire the capstone design project validation.

We have incorporated the key competencies into a portfolio of three modules. The Process Module (PM), includes those competencies which demonstrate learning about the processes involved in engineering design, modeling systems, and specifications of experiments, Our validation goal for this module is twofold: to measure the degree of acquisition and internalization of the more technical, and therefore the more quantitative, skills acquired in the design process and the appropriation of that knowledge to other processes the candidate might encounter in his professional career.

Competencies that compose the Human Skills Development Module (HSM), on the other hand, involve the acquisition of skills in such qualitative aptitudes as 
communication, networking, problem solving, and coordination and control of tasks and operations. We hope to validate the acquisition and internalization of learning of these skills through this module.

Our ultimate goal is to validate the level of competency synthesis achieved by each candidate. We hope to measure this through a focus on skills such as benchmarking relevant rivals in the design process, developing an appreciation for relationships among functions and components in design, and continuous infusion of new technologies into processes, These are captured in our Continuous Improvement Module (CIM).

While validating knowledge acquisition and internalization in all three modules, we measure the level of candidate learning by his/her ability to analyze, synthesize, and evaluate what s/he has learned. This will involve measuring how well the candidate is able to: solve problems s/he might have encountered with creative insight and the generation of multiple solution alternatives,

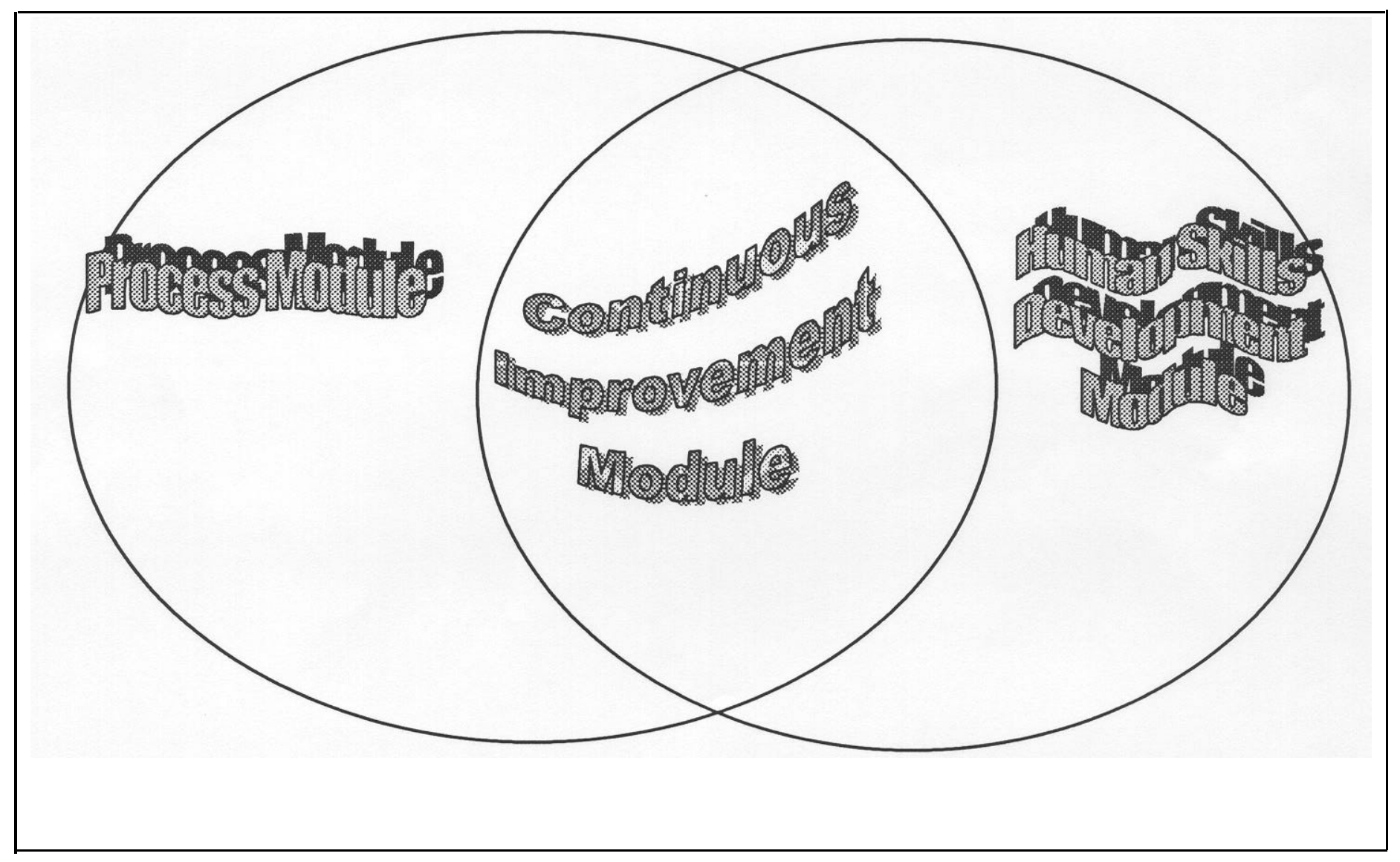

Fig. 1. The Interrelationship Among the three Modules

- respond to scrutiny by a team of validators composed of faculty, practicing professionals, and recent candidate graduates,

- identify critical assumptions, alternatives, and constraints in the design situation, 
- capture "capsule" descriptions of his/her project into a portfolio throughout his program on a template which we will devise and he/she will receive at the beginning of -his program; and,

- demonstrate logical consistency, efficiency, and objectivity in evaluating the integrity of the candidate's design.

Figure 1 describes the breakdown of each module we will develop and how these modules are interrelated.

\section{2.a. THE PROCESS MODULE}

By completing this module, each candidate will demonstrate understanding of (and/or appreciation for):

- The Engineering Design Process which involves:

- problem definition, a critical first step which will help the candidate formalize his initial vision of the project, its boundaries and key components;

- specification and requirement identification \& development, a task that will help the candidate frame his project;

- generation of alternative approaches toward solving the problem, a key competency in appreciating the multiplicity of pathways one should consider in approaching a design problem;

- evaluation of the merits of these approaches, an important skill that will help the candidate develop insight into merits of multiple approaches and the need to reach consensus or compromise among these sets of merits;

- feedback, response, and modification, an important factor in appreciating the value of revising one's initial design vision on light of new findings or stimuli;

- iteration, a key trait which will help the candidates appreciate the value added gained from continuous improvement in design;

- Modeling of systems, a necessary exercise in formalizing the candidate's vision of all the design systems; and,

- Characterizing/specifying the process, and performing design of experiments to improve the process, the final necessary step in continuously applying design principles to real design problems.

\section{2.b. HUMAN SKILLS DEVELOPMENT MODULE}

While difficult to acquire, internalize and appropriate, and even more difficult to measure their absorption by the candidates, human skills are nonetheless, critical competencies that must be internalized by the candidates for effective design project implementation. We have, therefore, incorporated this human skills development dimension into our project. We posit that, by completing this module, the candidate will demonstrate understanding of (and appreciation for):

- Communication, team building and participation (networking) skills, interpersonal skills that are primary prerequisities to effectively managing design projects; 
- Problem solving skills (both personal and interpersonal), skills that are key to developing analytical, evaluative, constructive, and most importantly, creative approaches to problem resolution. These skills might be operationalized by:

- continuous assessment of the capabilities and limitations of the system being worked on, and

- troubleshooting to unlock operational bottlenecks; and finally,

- Organizational skills, competencies that are key to understanding the inherent nature of a problem, decomposing it to glean into its multiple facets, and developing different ways of reconstructing it to identify and propose efficient design alternatives. These skills might be captured in:

- task design,

- decomposition,

- coordination, and

- control.

\section{2.c. THE CONTINUOUS IMPROVEMENT MODULE}

Of course, the acquisition, internalization, and appropriation of process and human skills can not be as effective without the glue that must graft them together. To accomplish this higher objective, we present a synthesis module focusing on continuous improvement. Our special focus on this module is inspired by our belief that effective learning is continuous; that synergies are generated when different sets of skills are bonded together, and that learning is paramount when competencies are renewed with the infusion of new knowledge with each iterative step. We therefore hypothesize that, by completing this module, the candidate will demonstrate understanding of, and appreciation for:

- The importance of vision, objectives, and the strategy that is used to operationalize that vision which might be captured by:

- benchmarking relevant rivals,

- continuous infusion of new technologies into the system \& process of design,

- continuous execution of process research,

- troubleshooting capabilities sharpened through the application of statistical tools \& analysis, and

- appreciating interrelationships among functions;

- The importance of internalizing diversity and multicultural design environments as a personal and process value which might be personified by:

- valuing multiple work styles and work environments,

- Establishing reliability in operations to assure integrity in design, and

- Assuring customer satisfaction and social responsibility.

\section{METHODOLOGY}

The ultimate purpose of our project is to develop a portfolio of evaluation methods to validate the level of focused competency internalization and synthesis by the GC candidate. This development process will involve four tasks: scale development, evaluation and mentorship team development, symposium preparation, and written report preparation. 
The Validation Scale Development task will involve two features: (i) template development, and (ii) scale development for appraising performance along the project time horizon.

(i) We prepare standardized templates that allows candidates to track their progress during their projects against the competencies targeted in all three modules by capturing capsule descriptions of their projects into a portfolio throughout their project periods. For example, candidates will record their progress along how they defined, then reshaped and reformatted their engineering technology problem; what alternative methods they generated (or could have generated) to solve the problem at hand; how they improved their problem solving skills through communication and interactions with a diverse set of fellow candidates and academic and industrial mentors; and, how they were able to apply and objectively evaluate the merits of various analytical tools, processes, and approaches to their design problem.

(ii) We also develop scales for appraising performance along the candidate's project time line. These scales measure progress not only by the candidates themselves, but also by their academic and industrial mentors, They are used in evaluations at (a) the start of the project, (b) at mid-project time, and (c) at the end of the project. The purpose of these measures is to provide feedback for corrective action,

As each candidate cohort group participates in this process, this will become a continuous improvement initiative, forever improving the scales with candidate input at each iteration. This unique feature is likely to eventually perfect these scales, and make them transferable to other Coalition, or even other industrial settings.

Develop Scrutiny Teams and Mentor-ships. We form scrutiny/mentor teams composed of recent candidate graduates, academic faculty, and engineering/technology practitioners to assure that industrial needs and requirements are properly incorporated into the integrity of the projects, and to ensure that target competencies have been acquired during the projects. Industrial mentors will typically be practicing engineers in Detroit's manufacturing sector. In some cases, they will be recent GC graduates. They will meet with the candidates periodically to provide input into project validation. This will typically involve assuring correspondence between the candidate's project experiences and the competencies contained in the three modules, and coaching the candidate through the evaluation process. Hence, mentors will provide managerial, in addition to technical advice, and they will be in close contact with their faculty counterparts to assure harmony in communication and tasks,

Symposium Preparation. Each candidate's project experience is presented through three work products including a written report, candidate's oral scrutiny, and a portfolio presentation. These reports will compose the outcome documents on which the candidate's level of progress on each of the target competencies contained in the three modules will be validated. This will provide (a) the opportunity to continuously improve the evaluation methods, (b) incorporate ideas of external groups, and (c) enhance learning by present and prospective design candidates.

Written Report Preparation. The written report dimension of the validation process serves several functions. First, it helps us assess whether, and to what extent, many, though perhaps not all, of the competencies that compose three modules have been internalized, then synthesized, by the GC candidate. For instance, we will be able to 
evaluate the level of absorption of the problem definition, requirement identification and specification dimensions of our modules by the GC candidate, Second, by placing the candidate's written work against a formal 'written report" tutorial helps us guide the candidate's work formally, document potential deficiency areas, and allow swift corrective action. Finally, this report assists the GC candidate satisfy the intensive writing requirements of the design project through which he/she will earn credits at WSU.

\section{CONCLUSION}

In this paper, we presented the development of a portfolio of alternative validation methods for the Design Project Knowledge area towards a senior capstone design course in engineering technology at WSU. The methods will be developed to transport the lessons learned from this project to other educational institutions and the business community. This will involve documentation of the finalized frame of standards, a description of alternative modes of institutional adaptation and delivery, and suggestions for verification and assessment in those settings.

\section{$\underline{\text { References }}$}

[1] D. Landman, "A Method for Teaching Product Design for Production," ASME Annual Meeting, 1993.

[2] D. Myszka, "Design and Development in the Classroom," ASME Annual Meeting, 1993.

[3] Doepker, "Implementing the Product Realization Process in the Design Sequence," ASME Annual Meeting, 1993.

[4] R. Grant, R. Shani, R. Krishnan, “TQM's Challenge to Management Theory and Practice," Sloan Management Review, pp. 25-35, 1994.

[5] S. Walesh, "Engineering Your Future," Prentice-Hall, 1995.

[6] R. L. Mertz, “A Capstone Design Course," IEEE Transactions on Education, Feb. 1997.

[7] "Engineering Criteria 2000 - Criteria for Accrediting Programs in Engineering in the United States," ASEE Prism, pp. 41-42, March 1997.

[8] G. E. Dieter, "Engineering Design -- A Materials and Processing Approach," $2^{\text {nd }}$ edition, McGraw Hill, 1991.

[9] D. G. Ullman, "The Mechanical Design Process,” $2^{\text {nd }}$ edition, McGraw Hill, 1992.

[10] A. Eide at all, "Introduction to Engineering Design,” McGraw Hill, 1998.

[11] A. Eide at all, "Introduction to Engineering Problem Solving," McGraw Hill, 1998. 